\title{
Professor Dov Leshchinsky is the Winner of the 2014 Fumio Tatsuoka Best Paper Award
}

\author{
Jonathan T. H. Wu • Hoe I. Ling
}

(C) Springer New York 2015

Professor Dov Leshchinsky is selected by the Transportation Infrastructure Geotechnology as the winner of the Fumio Tatsuoka Best Paper Award. The award is being presented for the first time since it was established. The Journal recognizes Prof. Leshchinsky's groundbreaking research presented in the paper "Framework for Limit State Design of Geosynthetic-Reinforced Walls and Slopes" (Volume 1, No. 2, pp. 129164, 2014). The paper summarizes his keynote lecture delivered at the International Symposium on Design and Practice of Geosynthetic-Reinforced Soil Structures held in Bologna, Italy (14-16 October 2013), which was organized in honor of his research achievement.

J. T. H. Wu

University of Colorado Denver, Denver, CO, USA

e-mail: jonathan.wu@ucdenver.edu

H. I. Ling $(\bowtie)$

Columbia University, New York, NY, USA

e-mail: ling@civil.columbia.edu 


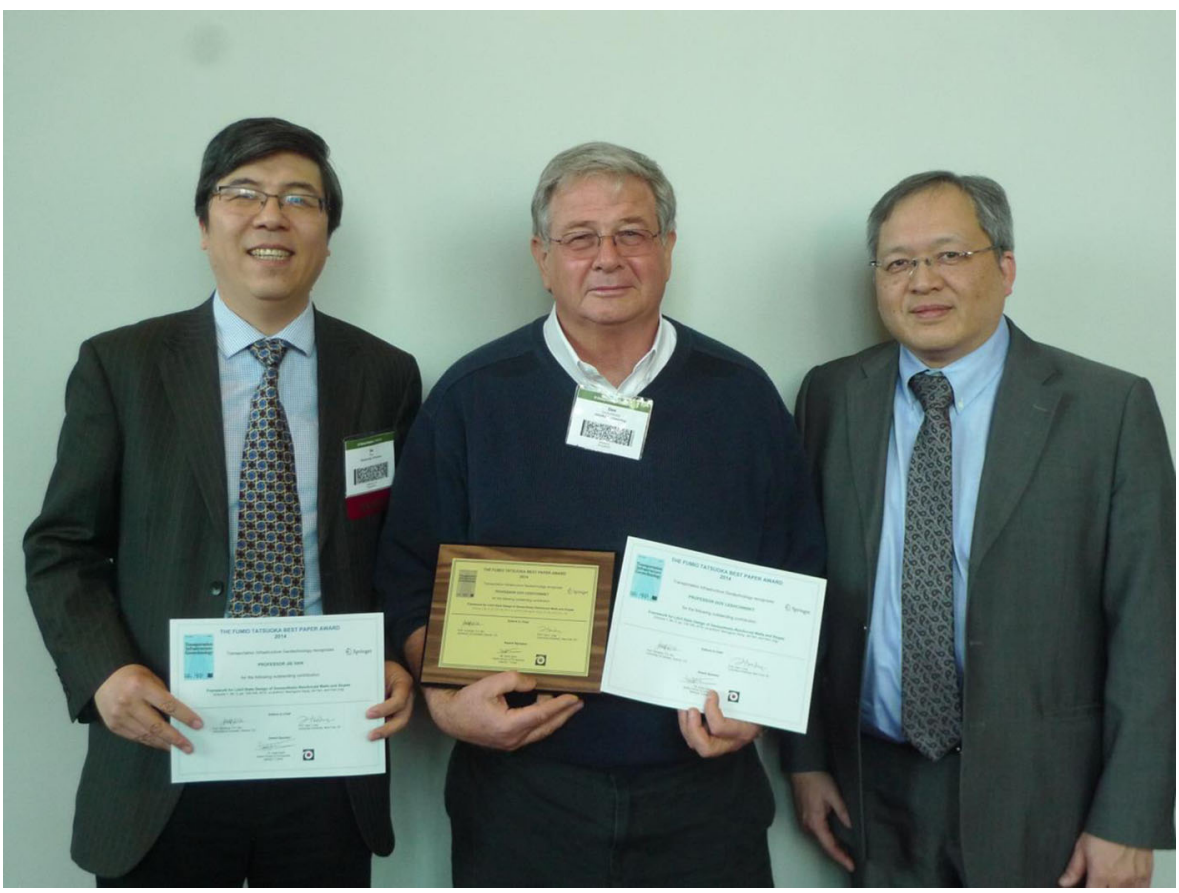

Prof. Leshchinsky was presented an award plaque during the Geosyntheics 2015 Conference held in Portland, Oregon. The co-authors were given a certificate associated with the award.

From left: Prof. Jie Han (co-author), Prof. Dov Leshchinsky, Prof. Hoe I. Ling

Prof. Leshchinsky is currently a Professor Emeritus at the University of Delaware where he served as a faculty member in the Department of Civil and Environmental Engineering from 1982 to 2014. He is also a consultant with Adama Engineering, Inc. Dr. Leshchinsky received his bachelor's and master's degrees at the Technion-Israel Institute of Technology and his doctorate at the University of Illinois at Chicago. His research contributions are in the areas of slope stability engineering and geosynthetics engineering, which includes soil reinforcing and ground improvement. He has developed design methods, including those for geosynthetic reinforced slopes and walls, and geotextile tubes that are being used worldwide. He co-developed software for the US Army Corps of Engineers, Federal Highway Administration, and private industry. A series of softwares he co-developed, namely MSEW, ReSSA, FoSSA, ReSlope, and GeoCoPS, has been used in the design of major earth structures. He was involved as an expert in forensic studies of failed MSE walls. Dr. Leshchinsky has taught numerous short courses on MSE walls and slopes worldwide as well as National Highway Institute courses to various State Departments of Transportation. In 2010, he received the Martin S. Kapp Foundation Engineering Award, ASCE: "For his innovative contribution to the unified method of design and analysis of earth retaining structures and slopes as well as implementation of such technology through computer software and continuing education." 
The Fumio Tatsuoka Best Paper Award was established in 2014 to recognize an individual's outstanding contribution to Transportation Infrastructure Geotechnology. Professor Fumio Tatsuoka is a leading researcher in the field of soil mechanics and geotechnical engineering. He holds bachelor's, master's, and doctoral degrees from the University of Tokyo. After spending several years as a research engineer at the Public Works Research Institute (Ministry of Construction, Japan), he became an associate professor and subsequently a full professor at the University of Tokyo. Since 2004, he is a full professor at the Tokyo University of Science. Professor Tatsuoka's past leading professional roles include President of the International Geosynthetics Society, Vice President of the International Society of Soil Mechanics and Geotechnical Engineering, Vice president of the Japanese Society of Civil Engineers, and President of the Japanese Geotechnical Society. His major research has been in the field of laboratory testing of geomaterials, deformation and strength characteristics of geomaterials, soil reinforcement with geosynthetics, foundation engineering, and ground improvement.

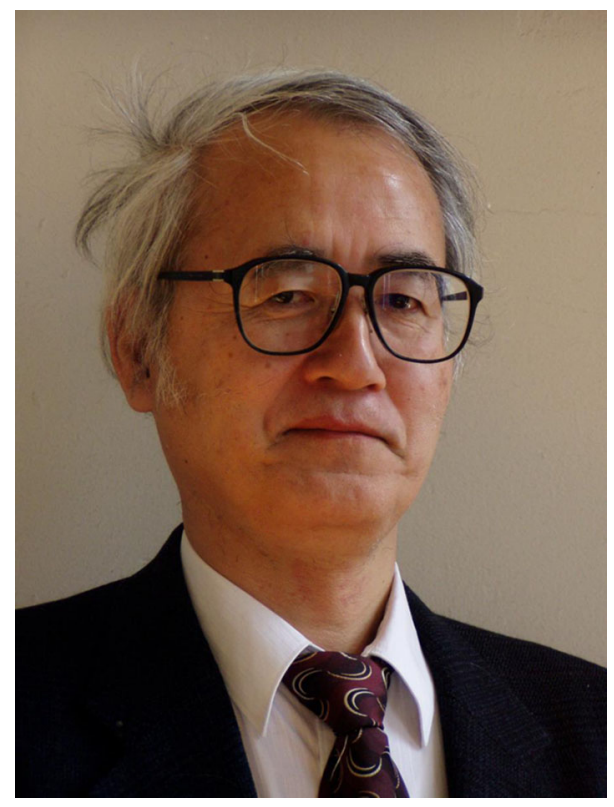

Professor Fumio Tatsuoka

The 2014 Award was sponsored by Mr. Izzet Garih, the Vice Chairman of the Board, Alarko Group of Companies, which is based in Istanbul, Turkey. 